\title{
A CLINICAL STUDY OF PATIENTS WITH IDIOPATHIC THROMBOCYTOPENIC PURPURA
}

\author{
KARTHIK RAO ${ }^{1}$, GURUKANTH RAO N ${ }^{2}$, NAVIN PATIL ${ }^{3 *}$, BALAJI $0^{3}$, RAO NR ${ }^{4}$, JAYAPRAKASH RAO ${ }^{5}$, SATISH NAYAK ${ }^{6}$
}

${ }^{1}$ Department of Internal Medicine, Kasturba Medical College, Manipal University, Manipal, Karnataka, India. ${ }^{2}$ Consultant Physician, Aster Clinic, Dubai. ${ }^{3}$ Department of Pharmacology, Kasturba Medical College, Manipal University, Manipal, Karnataka, India. ${ }^{4}$ Consultant, Anugraha Medical Center, Udupi, Karnataka, India. ${ }^{5}$ Department of Medicine, Kasturba Medical College, Manipal, Karnataka, India. ${ }^{6}$ Department of Gastroenterology, Apollo, Chennai, Tamil Nadu, India. Email: navin903@gmail.com

Received: 29 March 2017, Revised and Accepted: 22 April 2017

\section{ABSTRACT}

Objective: Idiopathic thrombocytopenic purpura (ITP) is an immuunological disorder characterized by the production of antibodies targeted toward platelets. Corticosteroids and intravenous immunoglobulins were the mainstay of immediate treatment after 1950 s with splenectomy for more than 100 years remains the only option with curative potential. The aim of this study was to analyze the incidence, age and sex distribution among adults, various modes of presentation, correlation between thrombocytopenia and bleeding manifestations, and various modalities of treatment of ITP in a tertiary care hospital in India..

Methods: A prospective study included 40 cases of ITP admitted to Kasturba Medical College Hospital, Manipal, from November 2005 to March 2007. Patients above 14 years of age admitted with thrombocytopenia in this institution were screened based on detailed clinical history, physical examination, and laboratory investigations.

Results: The maximum incidence was in the $3^{\text {rd }}$ decade of life accounting for $27.5 \%$ of the patients. Male-to-female ratio was $1: 1.9$ with female preponderance. Females in the $3^{\text {rd }}$ decade had maximum incidence while males in the $4^{\text {th }}$ decade have maximum incidence. The majority (12, $85.71 \%$ ) of male patients and $15(57.69 \%)$ female patients developed purpura during the course of disease. The mean count was $17.8 \times 10^{9} / \mathrm{L}$ with range between $2.0 \times 10^{9} / \mathrm{L}$ and $76 \times 10^{9} / \mathrm{L}$. Cutaneous bleeding spots were found to be associated with counts above $25000 \times 10^{9} / \mathrm{L}$ and hematuria with lowest counts around $4000 \times 10^{9} / \mathrm{L}$. A number of $20(50 \%)$ of the above 40 patients responded to corticosteroids alone and did not have any further relapse. Among the remaining patients, $3(7.5 \%)$ had a relapse of symptoms within next 6 months and responded to repeat prednisolone started at 1 mg/kg. $2(5 \%)$ patients were given steroids tapering dose with IV immune globulins for initial 5 days as therapy to which they responded.

Conclusion: Idiopathic thrombocytopenia is 1.9 times more common in females than males. Most common presentation is bleeding spots over body. Bleeding manifestations are more common with thrombocytopenia $<30000 / \mathrm{mm}^{3}$. Corticosteroids are the mainstay in treatment. Complete remission is seen in up to $57.5 \%$ of the patients. Splenectomy is the second modality of treatment in ITP. Complete and sustained remission is seen $75 \%$ of patients.

Keywords: Idiopathic thrombocytopenic purpura, Splenectomy, Steroids, Purpura.

(c) 2017 The Authors. Published by Innovare Academic Sciences Pvt Ltd. This is an open access article under the CC BY license (http://creativecommons. org/licenses/by/4. 0/) DOI: http://dx.doi.org/10.22159/ajpcr.2017.v10i7.18775

\section{INTRODUCTION}

Platelets are one of the three formed elements other than red and white blood cells which are seen in blood. These cells play an important role as far as hemostasis in the body is concerned. Platelets are susceptible to various forms of injury such as drugs, toxins, and viruses other than antibodies which destroy them by autoimmune mechanism [1,2]. Thus, idiopathic thrombocytopenic purpura (ITP) can be considered as an immunological disorder that has received lot of attention in recent years. In 1735, a German physician Paul Gottlieb Werlhof described ITP nearly 10 decades before Victor Hugo's published his novel Les misérables. ITP has an incidence of $6 / 100000$, and the licensing of thrombopoietin mimetic agents has added a good paradigm to its management $[3,4]$. Corticosteroids and intravenous immunoglobulins were the mainstay of immediate treatment after 1950's with splenectomy for more than 100 years remains the only option with curative potential. The center point in pathogenesis of this disorder is the production of antibodies targeted toward platelets as a result of derangement in immunological machinery of body wherein body fails to recognize these miniature cells as self. These antibodies get attached to platelets, which are destroyed and filtered off by the spleen. This results in decrease in number of platelets in peripheral blood giving rise to platelet manifestations [5].

There have been few numbers of studies carried out on ITP, but only a very few are in Indian subcontinent. This study was undertaken on ITP to study the incidence, age and sex distribution among adult, various modes of presentation, correlation between thrombocytopenia and bleeding manifestations, and various modalities of treatment instituted in this hospital.

\section{METHODS}

A prospective study consists of 40 cases of ITP admitted to Kasturba Medical College Hospital, Manipal, from November 2005 to March 2007. Ethical approval was taken from the institutional ethical board. Patients above 14 years of age admitted with thrombocytopenia in this institution were screened based on detailed clinical history, physical examination, and laboratory investigations. All patients were inpatients, in whom detailed workup was done in hospital.

\section{Inclusion criteria*}

1. Platelet count $<1,00,000 / \mathrm{mm}^{3}$

2. Megakaryocyte hyperplasia on bone marrow examination

3. Positive antiplatelet antibody test.

* Peripheral blood examination, bone marrow examination, antiplatelet antibody test, platelet factor 3 assay, antinuclear antibody, and human immunodeficiency virus by enzyme-linked immunosorbent assay were done to all patients. 
Exclusion criteria*

1. History of recent ingestion of drugs known to cause thrombocytopenia

2. Clinical or laboratory evidence of microangiopathy or disseminated intravascular coagulation

3. Clinical evidence of chronic liver disease with portal hypertension or any evidence of hypersplenism

4. The presence of clinical evidence sufficient to diagnose connective tissue diseases such as rheumatoid arthritis or systemic lupus erythematosus at presentation.

\section{RESULTS}

Forty patients of more than 14 years old admitted during the study were analyzed for age distribution. Patients varied from the second to $8^{\text {th }}$ decades with the youngest patient being 15 years old and oldest being 75 years old. The maximum incidence was in the $3^{\text {rd }}$ decade of life accounting for $27.5 \%$ of the patients (Table 1 and Fig. 1).

Of the total 40 patients, 14 were male and 26 were female. Male: female ratio was 1:1.9 with female preponderance (Table 2 and Fig. 2). Females in the $3^{\text {rd }}$ decade had maximum incidence while males in the $4^{\text {th }}$ decade have maximum incidence (Table 3 and Fig. 3). Among male patients, cutaneous bleeding spots including petechiae, purpura, and ecchymosis were the most common presenting symptoms. There was no predilection for any part of the body. The other presenting symptoms were bleeding gums, epistaxis, malena, and hematuria (Table 4 and Fig. 4).

Cutaneous bleeding spots $(10,38.46 \%)$ were the most common initial presenting symptom in females also. Menorrhagia $(26.72 \%)$ was the initial presenting symptom in a significant percentage of patients in our study. Other less common presentations in females were bleeding gums, epistaxis, malena, hematuria, and hemoptysis (Table 5 and Fig. 5). The majority $(12,85.71 \%)$ of male patients and $15(57.69 \%)$ female patients developed purpura during the course of disease. Other common manifestations were gum bleeding in males $(28.57 \%)$ and females $(34.61 \%)$, easy bruisability in females $(11.53 \%)$ and males $(21.42 \%)$, epistaxis in females $(15.38 \%)$, malena in females $(11.53 \%)$, and hematuria in males (14.28\%). Menorrhagia (42.30\%) was the second most common presentation in females (Table 6 and Fig. 6). One male and female patient had mild splenomegaly with tip of spleen palpable $2 \mathrm{~cm}$ below the left costal margin without any clinical or investigational features (anti-nuclear antibody negative) to suggest a secondary cause for thrombocytopenia.

The mean count was $17.8 \times 10^{9} / \mathrm{L}$ with range between $2.0 \times 10^{9} / \mathrm{L}$ and $76 \times 10^{9} / \mathrm{L}$. It was seen that 19 patients $(42 \%)$ had platelets between 10 and $30 \times 10^{9} / \mathrm{L}$ with 14 patients having platelet count $<10 \times 10^{9} / \mathrm{L}$ (Table 7). Correlation between the platelet count and clinical features of the patient at time of presentation (Table 8) was found and cutaneous bleeding spots were found to be associated with counts above $25000 \times 10^{9} / \mathrm{L}$ and hematuria with lowest counts around $4000 \times 10^{9} / \mathrm{L}$.

All patients were started on prednisolone at $1 \mathrm{ml} / \mathrm{kg}$ as initial therapy. Of 40 patients, $20(50 \%)$ responded to corticosteroids alone and did not have any further relapse. The corticosteroids were tapered over a period of 4-6 weeks and stopped. Among the remaining patients, $3(7.5 \%)$ had a relapse of symptoms within next 6 months and responded to repeat prednisolone started at $1 \mathrm{mg} / \mathrm{kg}$ and tapered over 6 weeks. These patients responded completely and did not have any further symptoms. Another $4(10 \%)$ patients who relapsed were started on dapsone along with steroids as therapy of which $1(2.5 \%)$ patient was also started on danazol, all patients responded to therapy over a period of 6-8 weeks without further relapse. $2(5 \%)$ patients were given steroids tapering dose with IV immune globulins for initial 5 days as therapy to which they responded (Table 9).

* Peripheral blood examination, bone marrow examination, antiplatelet antibody test, platelet factor 3 assay, antinuclear antibody, and human immunodeficiency virus by enzyme-linked immunosorbent assay were done to all patients
Table 1: Distribution of cases according to age

\begin{tabular}{ll}
\hline Age group (years) & Number of patients (\%) \\
\hline $14-20$ & $7(17.5)$ \\
$21-30$ & $11(27.5)$ \\
$31-40$ & $9(22.5)$ \\
$41-50$ & $6(15)$ \\
$51-60$ & $4(10)$ \\
$>60$ & $3(7.5)$ \\
\hline
\end{tabular}

Table 2: Distribution of patients according to sex

\begin{tabular}{ll}
\hline Sex & Number (\%) \\
\hline Males & $14(35)$ \\
Females & $26(65)$ \\
\hline
\end{tabular}

Table 3: Distribution of cases according to sex and age of patients

\begin{tabular}{llll}
\hline Age (years) & Number of patients & Males & Females \\
\hline $14-20$ & 7 & 4 & 3 \\
$21-30$ & 11 & 1 & 10 \\
$31-40$ & 9 & 5 & 4 \\
$41-50$ & 6 & 4 & 2 \\
$51-60$ & 4 & 1 & 3 \\
$>60$ & 3 & 1 & 2 \\
\hline
\end{tabular}

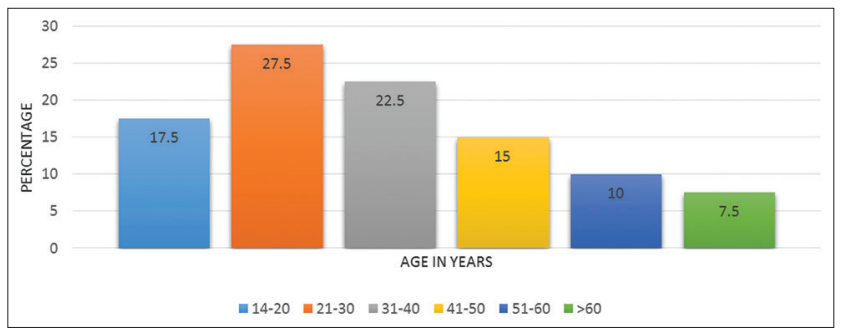

Fig. 1: Distribution of cases as per age

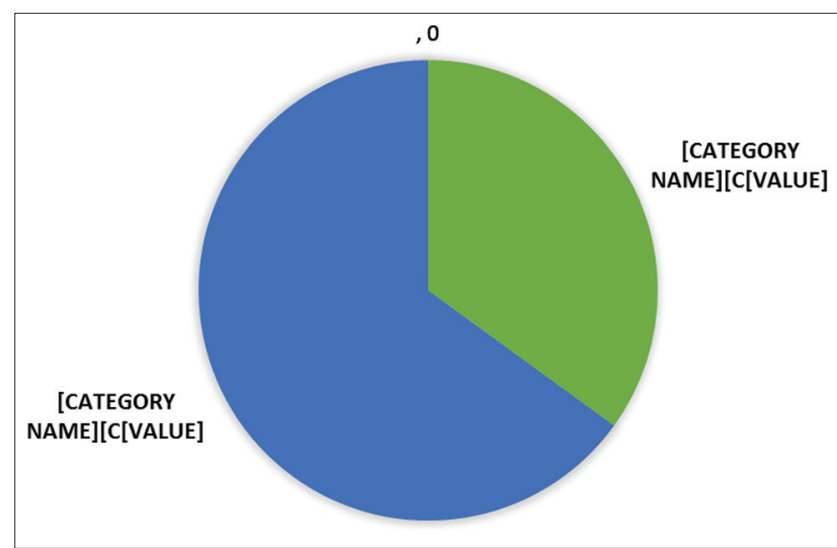

Fig. 2: Sex-wise distribution of idiopathic thrombocytopenic purpura

Among the remaining 13 (32.5\%) patients who did not have an adequate response or patients who relapsed to initial medical therapy with steroids alone or along with immunosuppressive treatment, $8(20 \%)$ had splenectomy done to which 6 had adequate response and complete remission. One of the two patients who did not have a response is steroid dependent on low-dose prednisolone, having recurrence of symptoms on stopping steroids. The another patient with inadequate response to splenectomy is on therapy 


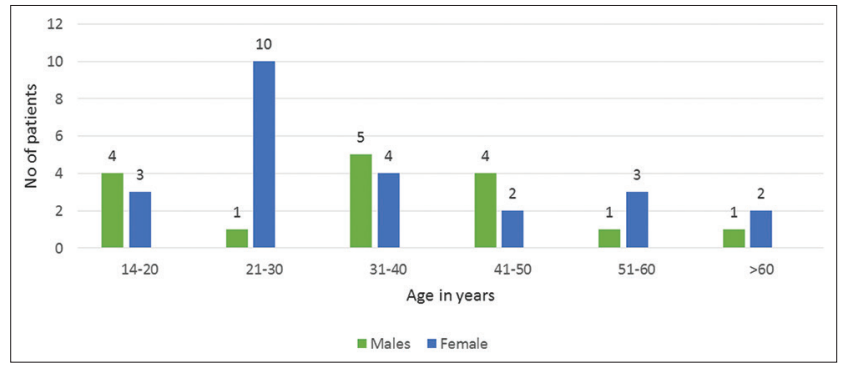

Fig. 3: Distribution of cases as per sex and age

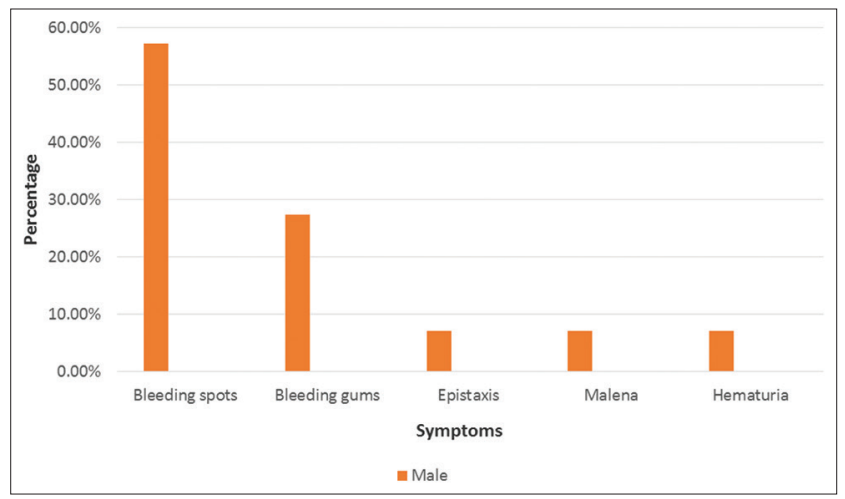

Fig. 4: Presenting symptoms males

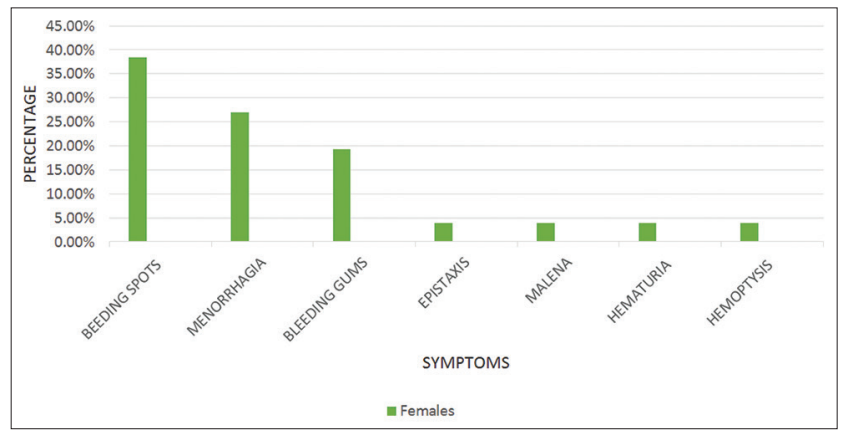

Fig. 5: Presenting symptoms females

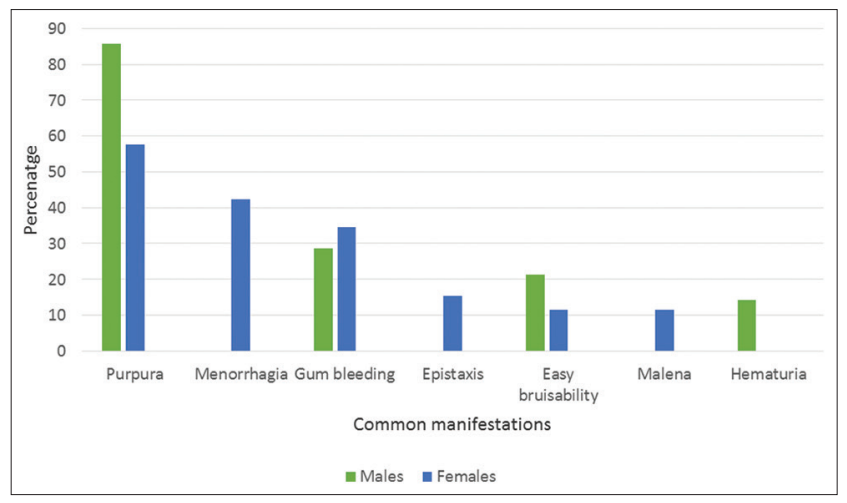

Fig. 6: Common manifestations of idiopathic thrombocytopenic purpura in males and females

with danazol. Among the remaining $5(12.5 \%)$ patients, 3 (7.5\%) are steroid dependent on low-dose maintenance steroids with oral prednisolone. One patient is on dapsone therapy, another patient was initially started on dapsone, but it was discontinued due to development of methemoglobinemia and is on treatment with azathioprine.
Table 4: Presenting symptoms of male patients

\begin{tabular}{ll}
\hline Symptom presentation & Number of patients male (\%) \\
\hline Cutaneous bleeding spots & $8(57.14)$ \\
Bleeding gums & $3(21.42)$ \\
Epistaxis & $1(7.14)$ \\
Malena & $1(7.14)$ \\
Hematuria & $1(7.14)$ \\
\hline
\end{tabular}

Table 5: Symptoms female patients

\begin{tabular}{ll}
\hline Symptoms & Number of patients (\%) \\
\hline Cutaneous bleeding spots & $10(38.46)$ \\
Menorrhagia & $7(26.92)$ \\
Bleeding gums & $5(19.23)$ \\
Epistaxis & $1(3.84)$ \\
Malena & $1(3.84)$ \\
Hematuria & $1(3.84)$ \\
Hemoptysis & $1(3.84)$ \\
\hline
\end{tabular}

Table 6: Common manifestations of ITP in male sand females

\begin{tabular}{lll}
\hline Clinical features & Males (\%) & Females (\%) \\
\hline Purpura & $12(85.17)$ & $15(57.69)$ \\
Menorrhagia & - & $11(42.30)$ \\
Gum bleeding & $4(28.57)$ & $9(34.61)$ \\
Epistaxis & - & $4(15.38)$ \\
Easy bruisability & $3(21.42)$ & $3(11.53)$ \\
Malena & - & $3(11.53)$ \\
Hematuria & $2(14.28)$ & - \\
\hline
\end{tabular}

ITP: Idiopathic thrombocytopenic purpura

Table 7: Platelet count in idiopathic thrombocytopenia

\begin{tabular}{ll}
\hline Platelet count $\times \mathbf{1 0} \boldsymbol{9} / \mathbf{L}$ & Number of patients (\%) \\
\hline$<10$ & $14(35)$ \\
$10-30$ & $19(47.5)$ \\
$31-50$ & $5(12.5)$ \\
$51-100$ & $2(5)$ \\
\hline
\end{tabular}

Table 8: Platelet count and clinical features at presentation

\begin{tabular}{ll}
\hline Clinical features & Mean platelet count $/ \mathbf{m m}^{\mathbf{3}}$ \\
\hline Cutaneous bleeding spots & 28432 \\
Gum bleeding & 25770 \\
Menorrhagia & 9832 \\
Easy bruisability & 23333 \\
Epistaxis & 17500 \\
Malena & 9000 \\
Hematuria & 4000 \\
\hline
\end{tabular}

Table 9: Modalities of treatment instituted

\begin{tabular}{ll}
\hline Treatment & Number of patients \\
\hline Corticosteroids & 40 \\
Splenectomy & 8 \\
Azathioprine & 2 \\
Danazol & 5 \\
Dapsone & 9 \\
IV Ig & 2 \\
\hline
\end{tabular}

IV Ig: Intravenous immune globulin

\section{DISCUSSION}

ITP refers to thrombocytopenia in which apparent exogenous factors are lacking and in which diseases known to be associated with 
secondary thrombocytopenia have been excluded. Females are affected 3-4 times more than males, and a seasonal fluctuation is noted with peak in spring and early summer and a nadir in winter. Acute ITP usually occurs in children $<6$ months and chronic ITP affects the adults. Pathophysiology of ITP includes inhibition of thrombopoiesis, platelet phagocytosis, antiplatelet antibody formation, antibody-mediated platelet destruction, and direct T-cell-mediated cytotoxicity against platelets in chronic ITP [5-15]. Clinically ITP presents as acute and chronic.

Acute ITP is usually sudden with history of infections preceding the bleeding by $2-3$ weeks in $84 \%$ of cases [16]. Bleeding manifestations are usually mild [17] and intracranial hemorrhage in $<1 \%$ of patients. It is usually self-limited with spontaneous remissions in $90 \%$ of cases [16]. Splenomegaly has been reported in $10 \%$ of patients [18]. The duration of disease ranges from few days to weeks with an average of 4-6 weeks [19]

Chronic ITP is insidious with long history of hemorrhagic symptoms of mild to moderate severity. Antecedent infections, fever, and splenic enlargement are uncommon with a fluctuating clinical course commonly seen. Spontaneous remissions are uncommon and are likely to be incomplete with cyclical or intermittent episodes of bleeding lasting few days to weeks. Relapses in some cases occur due to vaccination [20].

In this study, it was observed that ITP occurs over age group from $2^{\text {nd }}$ to $8^{\text {th }}$ decades with maximum incidence in the $3^{\text {rd }}$ followed by the $4^{\text {th }}$ decade. This observation is similar to that seen in other studies like those by Brown and Eliott [21], Portielje et al. [22], and Branehög et al. [23]. However, in a study conducted by Wong and Lee [24], the maximum incidence was in patients above 50 years followed by those in $4^{\text {th }}$ decade. With respect to sex distribution, $65 \%$ of patients in this study were female with male: female ratio of $1: 1.9$, similar to incidence seen in studies conducted by Branehög et al. [23] and Wong and Lee [24].

The overall most common presenting symptom was bleeding spots over the body. Purpuric spots were distributed all over the body without predilection to any specific site. In studies conducted by Difino et al. [25], Portielje et al. [22], and Wong and Lee [24], the most common mode of presentation was purpuric spots on body. Among the male patients, the second most presentation was bleeding gums whereas among female patients it was menorrhagia. Wong and Lee [24] also reported menorrhagia as a common presenting complaint in females. Doan et al. [19] had reported one patient whose only symptom was menorrhagia. In this study, there were three patients whose only symptom was menorrhagia. Lacey and Penner [26] had reported a case with history on intracranial bleed with no history of bleeding manifestation before that. A similar case was reported by Wong and Lee [24]. However, in the present study, no patient presented with intracranial bleed.

Splenomegaly is rarely found in patients with ITP. However, spleen may be palpable in $5 \%$ of patients as described by Doan et al. [19]. In the current study, 2 patients had mild splenomegaly. An attempt was made to correlate between the platelet count and clinical feature at presentation. Mean platelet counts varied from $28856 / \mathrm{mm}^{3}$ in patients with purpura to $4000 / \mathrm{mm}^{3}$ in patients with hematuria. This was similar to study conducted by Wong and Lee [24]. However, patients presented with menorrhagia at a higher platelet count in that study (Table 10).

Complete remission to steroids was observed in $57.5 \%$ of the patients. Studies conducted by Portielje et al. [22] and Wong and Lee [24] revealed remission in $67.7 \%$ and $46.7 \%$ of patients, respectively. About $75 \%$ of patients in the current study had sustained remission. Similar results were obtained in studies by Portielje et al. [22] with remission of $75 \%$ and that conducted by Wong and Lee [24] with remission of $64.9 \%$. Laros and Penner [27] and Caplan and Berkman [28] have reported
Table 10: Comparison of symptoms of our study with other studies

\begin{tabular}{lll}
\hline Symptom & Current study & Wong et al. \\
\hline Cutaneous bleeding spots & $28.8 \times 10^{9} / \mathrm{L}$ & $30 \times 10^{9} / \mathrm{L}$ \\
Menorrhagia & $9.8 \times 10^{9} / \mathrm{L}$ & $42 \times 10^{9} / \mathrm{L}$ \\
Hematuria & $4 \times 10^{9} / \mathrm{L}$ & $4.5 \times 10^{9} / \mathrm{L}$ \\
Malena & $9 \times 10^{9} / \mathrm{L}$ & $16 \times 10^{9} / \mathrm{L}$ \\
\hline
\end{tabular}

44-55\% response to azathioprine in patients with refractory ITP. In this study, three patients required maintenance immunosuppressive therapy.

\section{CONCLUSION}

Idiopathic thrombocytopenia is 1.9 times more common in females than males. Adults with ITP present between the second and $8^{\text {th }}$ decade with maximum incidence in the $3^{\text {rd }}$ and $4^{\text {th }}$ decades of life. Patients present with various hemorrhagic manifestations. Most common presentation is bleeding spots over body. Subsequently, they may develop symptoms of bleeding at other sites such as menorrhagia, epistaxis, malena, and hematuria. Splenic enlargement is very common in ITP. However, spleen may be just palpable in $5 \%$ of patients with this disorder. Severity of bleeding manifestations corresponds to degree of thrombocytopenia. Bleeding manifestations are more common with thrombocytopenia $<30000 / \mathrm{mm}^{3}$. Corticosteroids are the mainstay in treatment. Complete remission is seen in up to $57.5 \%$ of the patients. Splenectomy is the second modality of treatment in ITP. Complete and sustained remission is seen $75 \%$ of patients. Patients who do not have an adequate response can be treated with either immunosuppressive drugs or maintenance dose of corticosteroids.

\section{REFERENCES}

1. Lee SY, Chary M, Salehi I, Bansal R. Immune-mediated adalimumabinduced thrombocytopenia for the treatment of ulcerative colitis. Int J Pharm Pharm Sci 2015;7(7):456-8.

2. Balaji O, Patil N, Avinash A, Tilak A. Cefuroxime-induced thrombocytopenia: It's just not in the ring? Asian J Pharm Clin Res 2016;9(5):1-2.

3. Rao VK. ITP: Hematology's Cosette from Les Misérables. Blood 2013;121(11):1928-30.

4. Segal JB, Powe NR. Prevalence of immune thrombocytopenia: Analyses of administrative data. J Thromb Haemost 2006;4(11):2377-83.

5. Leung LL. Role of thrombospondin in platelet aggregation. J Clin Invest 1984;74(5):1764.

6. Roth GJ. Developing relationships: Arterial platelet adhesion, glycoprotein IB, and leucine-rich glycoproteins. Blood 1991;77(1):5-19.

7. Chang M, Nakagawa PA, Williams SA, Schwartz MR, Imfeld KL, Buzby JS, et al. Immune thrombocytopenic purpura (ITP) plasma and purified ITP monoclonal autoantibodies inhibit megakaryocytopoiesis in vitro. Blood 2003;102(3):887-95.

8. McMillan R, Wang L, Tomer A, Nichol J, Pistillo J. Suppression of in vitro megakaryocyte production by antiplatelet autoantibodies from adult patients with chronic ITP. Blood 2004;103(4):1364-9.

9. Nomura S, Dan K, Hotta T, Fujimura K, Ikeda Y. Effects of pegylated recombinant human megakaryocyte growth and development factor in patients with idiopathic thrombocytopenic purpura. Blood 2002;100(2):728-30.

10. Bussel JB, Kuter DJ, George JN, Aledort LM, Lichtin AE, Lyons RM, et al. Long-term dosing of AMG 531 is effective and well tolerated in thrombocytopenic patients with immune thrombocytopenic purpura. Blood 2005;106(11):220.

11. McMillan R, Wang L, Tani P. Prospective evaluation of the immunobead assay for the diagnosis of adult chronic immune thrombocytopenic purpura (ITP). J Thromb Haemost 2003;1(3):485-91.

12. Berchtold P, Beardsley D, Fujisawa K, Kaplan C, Lipp E, Morell-Kopp MC, et al. International study to compare antigen-specific methods used for the measurement of antiplatelet autoantibodies. Br J Haematol 1997;96(3):477-83.

13. Fabris F, Scandellari R, Ruzzon E, Randi ML, Luzzatto G, Girolami A. Platelet-associated autoantibodies as detected by a solid-phase modified 
antigen capture ELISA test (MACE) are a useful prognostic factor in idiopathic thrombocytopenic purpura. Blood 2004;103(12):4562-4.

14. Webster ML, Sayeh E, Crow M, Chen P, Nieswandt B, Freedman J, et al. Relative efficacy of intravenous immunoglobulin $\mathrm{G}$ in ameliorating thrombocytopenia induced by antiplatelet GPIIbIIIa versus GPIb $\alpha$ antibodies. Blood 2006;108(3):943-6.

15. Samuelsson A, Towers TL, Ravetch JV. Anti-inflammatory activity of IVIG mediated through the inhibitory Fc receptor. Science 2001;291(5503):484-6

16. Lusher JM, Zuelzer WW. Idiopathic thrombocytopenic purpura in childhood. J Pediatr 1966;68(6):971-9.

17. Kurtzberg J, Stockman $3^{\text {rd }}$ JA. Idiopathic autoimmune thrombocytopenic purpura. Adv Pediatr 1993;41:111-34.

18. McWilliams NB, Maurer HM. Acute idiopathic thrombocytopenic purpura in children. Am J Hematol 1979;7(1):87-96.

19. Doan CA, Bouroncle BA, Wiseman BK. Idiopathic and secondary thrombocytopenic purpura: Clinical study and evaluation of 381 cases over a period of 28 years. Ann Intern Med 1960;53(5):861-76.

20. Kelton JG. Vaccination-associated relapse of immune thrombocytopenia. JAMA 1981;245(4):369-71.
21. Brown DN, Eliott HE. The result of splenectomy inthrombocytopenic purpura. JAMA 1986;11:1781.

22. Portielje JE, Westendorp RG, Kluin-Nelemans HC, Brand A. Morbidity and mortality in adults with idiopathic thrombocytopenic purpura. Blood 2001;97(9):2549-54

23. Branehög I, Kutti J, Weinfeld A. Platelet survival and platelet production in idiopathic thrombocytopenic purpura (ITP). $\mathrm{Br} \mathrm{J}$ Haematol 1974;27(1):127-43.

24. Wong GC, Lee LH. A study of idiopathic thrombocytopenic purpura (ITP) patients over a ten-year period. Ann Acad Med Singapore 1998;27:789-93.

25. Difino SM, Lachant NA, Kirshner JJ, Gottlieb AJ. Adult idiopathic thrombocytopenic purpura: Clinical findings and response to therapy. Am J Med 1980;69(3):430-42.

26. Lacey JV, Penner JA. Management of idiopathic thrombocytopenic purpura in the adult. Semin Thromb Hemost 1977;3(3):160-74.

27. Laros RK, Penner JA. Refractory thrombocytopenic purpura treated successfully with cyclophosphamide. JAMA 1971;215(3):445-9.

28. Caplan SN, Berkman EM. Immunosuppressive therapy of idiopathic thrombocytopenic purpura. Med Clin N Am 1976;60(5):971-86. 